\title{
Emotional Intelligence and Clinical Symptoms in Outpatients with Generalized Anxiety Disorder (GAD)
}

\section{Nathalie P. Lizeretti \& Natalio Extremera}

\section{Psychiatric Quarterly}

ISSN 0033-2720

Volume 82

Number 3

Psychiatr Q (2011) 82:253-260

DOI 10.1007/s11126-011-9167-1
Volume 78 • Number $1 \cdot$ March 2007
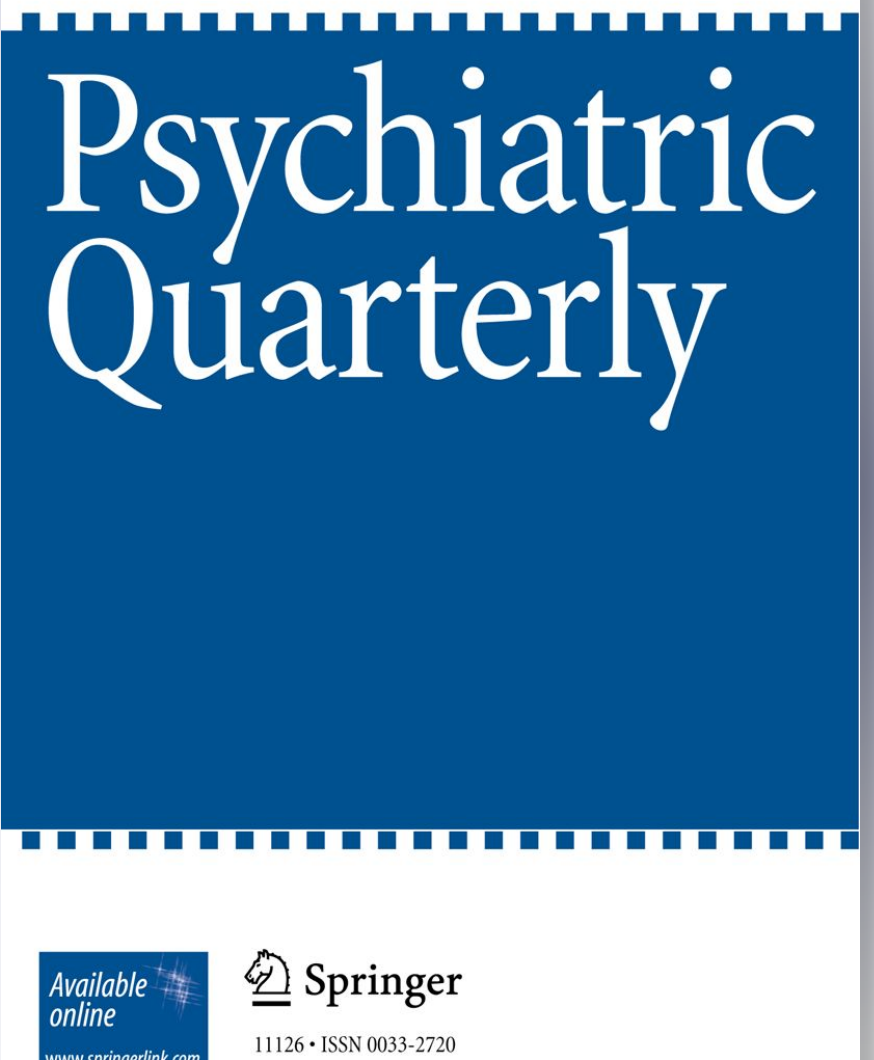

Springer

11126 • ISSN 0033-2720

78(1) 000-000 (2007) 
Your article is protected by copyright and all rights are held exclusively by Springer Science+Business Media, LLC. This e-offprint is for personal use only and shall not be selfarchived in electronic repositories. If you wish to self-archive your work, please use the accepted author's version for posting to your own website or your institution's repository. You may further deposit the accepted author's version on a funder's repository at a funder's request, provided it is not made publicly available until 12 months after publication. 


\title{
Emotional Intelligence and Clinical Symptoms in Outpatients with Generalized Anxiety Disorder (GAD)
}

\author{
Nathalie P. Lizeretti $\cdot$ Natalio Extremera
}

Published online: 30 January 2011

(C) Springer Science+Business Media, LLC 2011

\begin{abstract}
Generalized anxiety disorder (GAD) is the anxiety disorder with the highest prevalence rate in mental health centers. Empirical researches concerning its diagnosis and treatment have not yet explored the potential implications of deficits in emotional intelligence (EI) as a vulnerability factor in its development. The present study aimed to investigate the relationship between EI and clinical symptoms in a group of psychiatric patients with GAD compared to the control group. Seventy outpatients (82.9\% female) with a DSM-IV-TR diagnosis of GAD and 70 control individuals (72.9\% female) completed self-report instruments assessing EI and clinical symptoms in a cross-sectional study. Significant correlations were observed between EI dimensions such as clarity $(r=.327)$ and repair $(r=.405)$ and symptoms of anxiety. Also, the dimensions of attention and repair allowed a clear discrimination between clinical patients and control group. The results of the present study showed that deficits in EI abilities were a vulnerability factor in the development of GAD.
\end{abstract}

Keywords Emotional intelligence - Generalized anxiety disorder - Clinical symptoms · Trait meta-mood scale

Generalized anxiety disorder (GAD) has one of the highest prevalence rates in mental health centers and primary healthcare [1]. GAD is characterized by excessive worry about a wide range of events and situations. In $90 \%$ of cases, GAD is accompanied by one or more of the following: somatic symptoms, depression, somatization, bipolar disorder or substance abuse [2]. These symptoms cause considerable deterioration in the social

N. P. Lizeretti

Sanitary Consortium of Maresme, Mataró, Spain

N. P. Lizeretti $(\bowtie)$

FPCEE Blanquerna, Ramon Llull University, C/Císter 34, 08022 Barcelona, Spain

e-mail: nathaliepl@blanquerna.url.edu

N. Extremera

Department of Social Psychology, University of Málaga, Málaga, Spain 
functioning [3] and quality of life of the patients [4]. Yet scarce research has focused on the emotional and psychopathological mechanisms involved in GAD [5].

In recent years there has been growing interest in identifying the affective mechanisms related to people's mental health. In this context, Mayer and Salovey [6] propose a model that defines emotional intelligence (EI) as a set of abilities to identify, understand, use and regulate emotions to promote greater emotional and personal growth. Various studies suggest that higher levels of EI are related to greater feelings of well-being, more positive moods and higher levels of self-esteem, optimism and life satisfaction [7]. Similarly, other studies have found that high scores in EI are associated to lower levels of depression and stress $[8,9]$.

To consider EI a valid and useful construct, it is necessary not only to show its prediction of significant life outcomes but also its genuine value regarding other adjacent concepts. Several authors have raised concerns about the divergent validity of the construct of EI on other related but traditional concepts in the psychological and psychiatric field [10]. In this sense, it is interesting to conceptually distinguish EI from other classic constructs that refer to dispositional optimism-pessimism, personality and cognitive abilities.

Dispositional optimism-pessimism is defined in terms of generalized expectancies concerning important future positive (optimism) and negative outcomes (pessimism) [11], that is, it refers to a global generalized belief that positive/negative outcomes would be obtained. However, the TMMS evaluates 'reasonable operationalization of aspects of emotional intelligence' (p. 147) [12]. This scale does not directly tap people's emotional abilities but rather people's perceived beliefs about their emotional abilities. The intercorrelations between EI measured by TMMS and dispositional optimism-pessimism have not been found strongly redundant, supporting the idea that both constructs might involve relatively different emotional and cognitive processes [7]. In this line, while dispositional optimism-pessimism would be related to more global generalized expectancies of desirable or undesirable events, EI assessed by TMMS is a more specific construct, referring only to outcomes of understanding and mood regulation.

Another potential overlapping construct to emotional intelligence is personality. Moderate associations have been found between EI measured by TMMS and personality, especially with neuroticism and extraversion [13]. Nevertheless, this significant relation is not so surprising as emotional responding is a core feature of many personality constructs. In this line, neuroticism is primarily characterized by negative emotional experiences and a main feature of extraversion involves positive affectivity [14]. On the other hand, EI focuses specifically and solely on emotional aspects, while personality traits not only include affective aspects but also ways of behaving and thinking [15]. In spite of their obvious similarities, there are also important differences that suggest these constructs are not entirely synonymous. In fact, empirical evidences suggest that EI predicts meaningful outcomes above and beyond the contributions of personality factors [10, 13].

Finally, emotional intelligence and cognitive abilities share some similarities but also significant differences. EI is defined as an ability that emphasizes individual differences in the cognitive processing of affective information while cognitive abilities are best conceived as ability to process reasoning in different areas such as verbal, spatial or numeric, among others. In fact, its relation is at best minimal to low-moderate in research comparing TMMS and cognitive abilities [8].

To sum up, EI, dispositional optimism-pessimism, personality and cognitive abilities all refer to positive and personal qualities with some theoretical connections between them. However, although a partial overlap is observed between them, the construct of EI cannot be reduced to any of these. Hence, different authors have concluded that EI evaluated by 
the TMMS is conceptually different and adds value over and above these classic constructs [16].

The limited studies carried out in mental health show that patients have lower levels of EI than non-clinical subjects [17, 18]. Hertel and colleagues [19] found that it is possible to discriminate between the different clinical groups based on their levels of EI, specifically emotional understanding. These results also showed significant differences in EI between patients with different mental disorders. These findings suggest the existence of specific EI profiles for different psychopathologies [20].

Although studies with non-clinical population samples indicate that anxiety and stress are clearly related to low EI [7,9], research examining EI to clinical symptoms in patients with anxiety disorder have yet to be carried out. However, GAD is characterized by important difficulties and deficits in emotional management [21]. Patients with GAD experience emotions as threatening, and it is evident that experiential avoidance of the symptoms of anxiety result in attempts to avoid emotions [22]. Findings suggest that patients with GAD have difficulty in perceiving emotional experiences clearly and have tendency to intensify the experience and expression of negative emotions [21], indicating considerable problems with emotional regulation.

Taken into account the above considerations, the aim of the present study is to examine the relationship between EI and clinical symptoms in a group of psychiatric patients diagnosed with GAD.

\section{Method}

\section{Participants}

The sample comprised 140 participants; 70 patients (82.9\% female) aged between 18 and 65 years of age $(\mathrm{M}=41.37$; $\mathrm{SD}=10.67)$ met $\mathrm{DSM}-\mathrm{IV}-\mathrm{TR}$ criteria for $\mathrm{GAD}$ as the main Axis I diagnosis; 70 individuals in the control group, mainly university students $(72.9 \%$ female) aged between 18 and 45 years of age $(M=23.14$; $S D=5.97)$.

\section{Materials}

- Structured clinical interview for DSM-IV Axis I disorders (SCID-I) [23].

- Symptom Checklist 90 (SCL-90-R). This self-report instrument provides scores on nine clinical subscales: Somatization (SOM), Obsessive-Compulsive (OC), Interpersonal Sensitivity (IS), Depression (DEP), Anxiety (ANX), Hostility (HOS), Phobic Anxiety (PHOB), Paranoid Ideation (PAR) and Psychoticism (PSY), and 3 clinical indexes: Global Severity Index (GSI), Positive Symptom Total (PST) and Positive Symptom Distress Index (PSDI). SCL-90-R has adequate internal consistency and validity. Similarly, this instrument is considered a screening reliable measure for distinguishing between clinical and non-clinical groups [24].

- Trait Meta-Mood Scale (TMMS-24). The TMMS was designed to assess how people reflect upon their moods, and thus conceived as an index of perceived emotional intelligence. The scale has three factors that provide three subscale scores: Attention to Feelings (relating to monitoring of emotions); Clarity of Feelings (relating to the ability to discriminate between emotions); and Mood Repair (relating to the ability to regulate unpleasant moods or maintain pleasant moods). This instrument has demonstrated good 
psychometric properties, such as test-retest reliability, discriminant validity and convergent validity [25].

\section{Procedure}

Patients were recruited through the public Center for Mental Health in Mataró (Barcelona, Spain). The patients, who voluntarily accepted to take part in the research, received the questionnaires during a clinical assessment interview. The control sample completed questionnaire in group. At the beginning of the study a psychiatrist or psychologist used the SCID to confirm the patient's DSM-IV-TR diagnosis. Control subjects were chosen on the basis that they did not met the clinical criteria in any of the SCL-90-R scales.

\section{Results}

Means (M) and standard deviations (SD) are presented in Table 1. T-test showed that clinical group scores were significantly higher $(p<.001)$ than control group scores in all the variables. With respect to EI dimensions, clinical group scored higher in attention $\left(t_{(.138)}=-3.829 ; p<.001\right)$ and lower in repair $\left(t_{(.138)}=2,137 ; p<.034\right)$, but no significant differences in clarity were found. It is also important to note that along clinical group showed higher anxiety scores, as well as reported higher scores in depression, obsessive-compulsive and somatization. For control group, there was no clinical significance in the SCL-90-R subscale scores.

As can be seen in Table 2, significant correlations between EI and clinical symptoms were found. In clinical group, attention did not correlate with any clinical symptom. However, in control group attention positively correlates with depression, psychoticism, interpersonal sensitivity and with GSI and PST indexes.

However, in the clinical group, mood clarity correlated negatively with interpersonal sensitivity, anxiety, hostility, depression, psychoticism and obsessive-compulsive, as well as with GSI and PSDI indexes. Finally, the repair scores in individuals in the GAD group negatively correlated with hostility, anxiety, interpersonal sensitivity, psychoticism, depression and paranoid ideation and with GSI and PSDI indexes within the clinical group. In the control group, repair only correlated with phobic anxiety.

\section{Discussion}

The present study examined the association between the clinical symptoms of patients with GAD and the meta-knowledge they have about their own emotional states using a selfreport measure of EI. Results reveal that patients with GAD perceived themselves as experiencing fewer EI than non-clinical individuals. They were more tend to pay more attention to their emotions [21,26]. As Borkovec and colleagues suggest, fear of experiencing emotions that they feel to be threatening might lead patients to a higher hypervigilance of emotional states [27] in an attempt to understand their negative feelings. However, they generally have limited ability to understand the causes and origins of their own emotional states. The negative correlations between emotional clarity and clinical symptoms suggest that an adequate level of emotional understanding is necessary for healthy mental functioning $[9,22]$. Although individuals in the GAD group reported lower 
Table 1 Means and standard deviations for clinical and control groups

\begin{tabular}{|c|c|c|c|c|c|}
\hline Scales & Group & $\infty$ & M & SD & $p$ \\
\hline \multicolumn{6}{|l|}{ SCL-90 } \\
\hline \multirow[t]{2}{*}{ GSI } & Clinical & - & 1.61 & .78 & $.000 * *$ \\
\hline & Control & - & .41 & .23 & \\
\hline \multirow[t]{2}{*}{ PST } & Clinical & - & 55.43 & 24.09 & $.000 * *$ \\
\hline & Control & - & 27.83 & 14.98 & \\
\hline \multirow[t]{2}{*}{ PSDI } & Clinical & - & 2.30 & .57 & $.000 * *$ \\
\hline & Control & - & 1.29 & .29 & \\
\hline \multirow[t]{2}{*}{ SOM } & Clinical & .90 & 1.81 & 1.06 & $.000 * *$ \\
\hline & Control & .80 & .43 & .33 & \\
\hline \multirow[t]{2}{*}{$\mathrm{OC}$} & Clinical & .88 & 1.96 & .94 & $.000 * *$ \\
\hline & Control & .78 & .62 & .42 & \\
\hline \multirow[t]{2}{*}{ IS } & Clinical & .87 & 1.42 & .95 & $.000 * *$ \\
\hline & Control & .82 & .50 & .37 & \\
\hline \multirow[t]{2}{*}{ DEP } & Clinical & .92 & 2.06 & .99 & $.000 * *$ \\
\hline & Control & .87 & .44 & .29 & \\
\hline \multirow[t]{2}{*}{ ANX } & Clinical & .90 & 1.83 & .99 & $.000 * *$ \\
\hline & Control & .82 & .34 & .26 & \\
\hline \multirow[t]{2}{*}{ HOS } & Clinical & .83 & 1.18 & .96 & $.000 * *$ \\
\hline & Control & .82 & .25 & .26 & \\
\hline \multirow[t]{2}{*}{ PHOB } & Clinical & .85 & 1.18 & .92 & $.000 * *$ \\
\hline & Control & .66 & .17 & .26 & \\
\hline \multirow[t]{2}{*}{ PAR } & Clinical & .81 & 1.39 & .92 & $.000 * *$ \\
\hline & Control & .69 & .40 & .36 & \\
\hline \multirow[t]{2}{*}{ PSY } & Clinical & .85 & .93 & .77 & $.000 * *$ \\
\hline & Control & .75 & .24 & .22 & \\
\hline \multicolumn{6}{|l|}{ TMMS-24 } \\
\hline \multirow[t]{2}{*}{ Attention } & Clinical & .82 & 27.01 & 6.24 & $.000 * *$ \\
\hline & Control & .89 & 23.24 & 5.38 & \\
\hline \multirow[t]{2}{*}{ Clarity } & Clinical & .83 & 23.89 & 6.20 & .177 \\
\hline & Control & .88 & 25.24 & 5.60 & \\
\hline \multirow[t]{2}{*}{ Repair } & Clinical & .80 & 22.64 & 6.02 & $.034 *$ \\
\hline & Control & .85 & 24.80 & 5.91 & \\
\hline
\end{tabular}

$* * p<.01 ; * p<.05$

levels of mood clarity than the control group, levels of statistical significance were not reached.

Patients with GAD also show more difficulties in effectively repairing their negative moods. This result coincides with others EI studies in the field of psychopathology [17-19] and with previous empirical research that suggests that individuals with GAD show more heightened intensity of emotions, expressing negative, but not positive, moods more often, report more frequently negative reaction to self-emotions, and more difficulty in managing them [21]. 
Table 2 Correlations between EI and SCL-90-R scales

\begin{tabular}{|c|c|c|c|c|c|c|}
\hline & \multicolumn{2}{|c|}{ Attention } & \multicolumn{2}{|l|}{ Clarity } & \multicolumn{2}{|l|}{ Repair } \\
\hline & Clinic & Control & Clinic & Control & Clinic & Control \\
\hline SOM & -.086 & .142 & -.178 & .074 & -.135 & .032 \\
\hline $\mathrm{OC}$ & .021 & .105 & $-.288^{*}$ & -.018 & -.182 & .014 \\
\hline IS & .152 & $.372 * *$ & $-.347 * *$ & .066 & $-.387 * *$ & -.028 \\
\hline DEP & .044 & $.444 * *$ & $-.289 *$ & .090 & $-.339 * *$ & -.104 \\
\hline ANX & .116 & .195 & $-.327 * *$ & .022 & $-.405^{* *}$ & .041 \\
\hline HOS & .149 & .179 & $-.300^{*}$ & .010 & $-.410 * *$ & -.057 \\
\hline РHOB & .109 & .186 & -.105 & .145 & -.204 & $.305^{*}$ \\
\hline PAR & .241 & .132 & -.150 & -.103 & $-.263^{*}$ & -.022 \\
\hline PSY & .118 & $.391 * *$ & $-.297 *$ & -.052 & $-.345^{* *}$ & -.108 \\
\hline GSI & .090 & $.311 * *$ & $-.321 * *$ & .045 & $-.356^{* *}$ & -.028 \\
\hline PST & .149 & $.279 *$ & -.084 & -.017 & -.160 & -.048 \\
\hline PSDI & .024 & .165 & $-.262^{*}$ & .144 & $-.328 * *$ & .050 \\
\hline
\end{tabular}

$* * p<.01 ; * p<.05$

Despite our preliminary evidence on the predictive value of the deficits in EI in relation to GAD, certain limitations need to be addressed in further research. For example, bearing in mind that EI increases with age [6], future research should include groups which are comparatively homogenous in age. Another limitation related to the sample is the possible difference in intelligence between experimental and control groups. Since the control group consists of university students, there may be differences in intelligence between the two groups that should be controlled for further studies. However, the findings seem to show that correlations between EI evaluated by the TMMS and cognitive abilities are low to minimal [8] while the stronger link between cognitive ability and emotional intelligence is found when using EI performance measures [28]. Besides, even though several studies confirm the validity of self-report format for the study of EI [9, 21], future studies should also include other instruments such as EI performance tests. Despite these limitations, our results provide preliminary evidence suggesting that deficit of the ability to attend to, discriminate among, and manage emotions might represent a vulnerability factor in the development of GAD, in accordance with other studies [22].

One of the main advantages of the Salovey and Mayer EI model is that the authors proposed that EI abilities can be learned and developed [6]. Considering EI into our understanding of anxiety disorders has possible implications for prevention and treatment in clinical populations. Our beliefs about mood and emotions may affect the degree to which anxious individuals engage in processing and integrating the cognitive and emotional aspects of the experience [29]. Since the appropriate processing and integration of threatening emotions is necessary to avoid the development of emotional reactions and ruminative thoughts [12], taking into account the degree to which attitudes about mood and cognitive responses to emotion facilitate or impede emotional processing may be important in predicting risk of emotional disorders [30]. Intervening at the therapeutic level of beliefs about, and responses to, intense threatening emotions might be an important part of therapeutic efforts aimed at preventing the appearance of these maladaptive emotional reactions characteristic of patients with GAD. In this sense, recent studies have led preliminary support about EI training programs being effective at increasing emotional 
abilities in non-clinical population. [31]. More interestingly, Eack and colleagues [32] have found evidences that Cognitive Enhancement Therapy increases levels of EI in patients with schizophrenia. Finally, a pilot study suggests that an EI training program focused on developing abilities to perceive, use, understand and manage emotional information not only improved EI ability and emotional self-efficacy but also was found to significantly reduce anxiety symptoms in patients with GAD [33].

The findings of our research could make a contribution towards the understanding of a disorder which characteristically presents high levels of resistance to existing treatments [34] and suggest new lines of intervention utilizing a functional emotions perspective focused on developing the abilities of understanding and emotional regulation.

\section{References}

1. Katon W, von Korff M, Lin E, Lipscomb P: Distressed high utilizers of medical care: DSM-III-R diagnoses and treatment needs. General Hospital Psychiatry 12(6):355-362, 1990

2. Kessler R, McGonagle K, Zhao S, Nelson C: Lifetime and 12-month prevalence of DSM-III-R psychiatric disorders in the United States: Results from the national comorbidity study. Archives of General Psychiatry 51(1):8-19, 1994

3. Wittchen H, Zhao S, Kessler R, Eaton W: DSM-III-R generalized anxiety disorder in the national comorbidity survey. Archives of General Psychiatry 51(5):355-364, 1994

4. Roy-Byrne P, Katon W: Generalized anxiety disorder in primary care: The precursor/modifier pathway to increased health care utilization. Journal of Clinical Psychiatry 58(Suppl 3):34-40, 1997

5. Dugas M: Generalized anxiety disorder publications: So where do we stand? Journal of Anxiety Disorders 14(1):31-40, 2000

6. Mayer J, Salovey P: What is Emotional Intelligence? In: Salovey P, Sluyter DJ (Eds) Emotional Development and Emotional Intelligence: Educational Implications. New York, Basic Books, pp. 3-34, 1997

7. Extremera N, Durán A, Rey L: Perceived emotional intelligence and dispositional optimism-pessimism: Analyzing their role in predicting psychological adjustment among adolescents. Personality and Individual Differences 42(6): 1069-1079, 2007

8. Bastian V, Burns N, Nettelbeck T: Emotional intelligence predicts life skills, but not as well as personality and cognitive abilities. Personality and Individual Differences 39(6):1135-1145, 2005

9. Salovey P, Stroud L, Woolery A, Epel E: Perceived emotional intelligence, stress reactivity, and symptom reports: Further explorations using the trait meta-mood scale. Psychology and Health 17(5):611-627, 2002

10. Shulman T, Hemenover S: Is dispositional emotional intelligence synonymous with personality? Self and Identity 5(2):147-171, 2006

11. Scheier M, Carver C: Optimism, coping, and health: Assessment and implications of generalized outcome expectancies. Health Psychology 4(3):219-247, 1985

12. Salovey P, Mayer J, Goldman S, Turvey C, Palfai T: Emotional Attention, Clarity, and Repair: Exploring Emotional Intelligence Using the Trait Meta-Mood Scale. In: Pennebaker JW (Ed) Emotion, Disclosure, \& Health. Washington, American Psychological Association, pp. 125-154, 1995

13. Extremera N, Fernández-Berrocal P: Perceived emotional intelligence and life satisfaction: Predictive and incremental validity using the trait meta-mood scale. Personality and Individual Differences 39(5):937-948, 2005

14. Costa P, McCrae R: Normal personality assessment in clinical practice: The NEO personality inventory. Psychological Assessment 4(1):5-13, 1992

15. Pytlik Zillig L, Hemenover S, Dienstbier R: What do we assess when we assess a Big 5 trait? A content analysis of the affective, behavioral and cognitive processes represented in the Big 5 personality inventories. Personality and Social Psychology Bulletin 28(6):847-858, 2002

16. Berrocal P, Extremera N: A Review of Trait Meta-Mood Research. In: Columbus AM (Ed) Advances in Psychology Research, Vol. 55. Hauppauge, Nova Science Publishers, pp. 17-45, 2008

17. Downey L, Johnston P, Hansen K, Schembri R, Stough C, Tuckwell V, et al.: The relationship between emotional intelligence and depression in a clinical sample. European Journal of Psychiatry 22(2):93-98, 2008 
18. Kee K, Horan W, Salovey P, Sergi M, Lee J, Nuechterlein K, et al.: Emotional intelligence in schizophrenia. Schizophrenia Research 107(1):61-68, 2009

19. Hertel J, Schütz A, Lammers C: Emotional intelligence and mental disorder. Journal of Clinical Psychology 65(9):942-954, 2009

20. Hansen K, Lloyd J, Stough C: Emotional Intelligence and Clinical Disorders. In: Stough C, Saklofske DH, Parker JDA (Eds) Assessing Emotional Intelligence: Theory, Research, and Applications. New York, Springer, pp. 219-237, 2009

21. Mennin D, Heimberg R, Turk C, Fresco D: Preliminary evidence for an emotion dysregulation model of generalized anxiety disorder. Behaviour Research and Therapy 43(10):1281-1310, 2005

22. Roemer L, Salters K, Raffa S, Orsillo S: Fear and avoidance of internal experiences in GAD: Preliminary tests of a conceptual model. Cognitive Therapy and Research 29(1):71-88, 2005

23. First M, Spitzer R, Gibbon M, Williams J: Entrevista Clínica Estructurada para los Trastornos del Eje I del DSM-IV. Versión Clínica. Barcelona, Masson, 1999

24. Derogatis L: SCL-90-R: SCL-90-R: Administration, Scoring and Procedures Manual-II. Towson, Clinical Psychometric Research, 1983

25. Fernández-Berrocal P, Extremera N, Ramos N: Validity and reliability of the Spanish modified version of the trait meta-mood scale. Psychological Reports 94(3):751-755, 2004

26. Extremera N, Fernández-Berrocal P: Emotional intelligence as predictor of mental, social, and physical health in university students. Spanish Journal of Psychology 9(1):45-51, 2006

27. Borkovec T, Inz J: The nature of worry in generalized anxiety disorder: A predominance of thought activity. Behaviour Research Therapy 28(2):153-158, 1990

28. Warwick J, Nettelbeck T: Emotional intelligence is...? Personality and Individual Differences 37(5):1091-1100, 2004

29. Salovey P, Bedell B, Detweiler JB, Mayer J: Coping Intelligently: Emotional Intelligence and the Coping Process. In: Snyder CR (Ed) Coping: The Psychology of What Works. New York, Oxford University Press, pp. 141-164, 1999

30. Malterer M, Glass S, Newman J: Psychopathy and trait emotional intelligence. Personality and Individual Differences 44(3):735-745, 2008

31. Nelis D, Quoidbach J, Mikolajczak M, Hansenne M: Increasing emotional intelligence: (How) is it possible? Personality and Individual Differences 47(1):36-41, 2009

32. Eack S, Hogarty G, Greenwald D, Hogarty S, Keshavan M: Cognitive enhancement therapy improves emotional intelligence in early course schizophrenia: Preliminary effects. Schizophrenia Research 89(1-3):308-311, 2007

33. Lizeretti NP, Oberst U, Farriols N, Rodriguez A, Castell R: Anxiety Disorder Treatment: Assessment of Emotional Intelligence Focused Therapy. In: 2nd International Emotional Intelligence Congress, Santander, 2009

34. Durham R: Treatment of generalized anxiety disorder. Psychiatry 6(5):183-187, 2007

\section{Author Biographies}

Nathalie P. Lizeretti, PhD is a collaborator professor at the Department of Psychology at FCEE Blanquerna Ramon Llull University of Barcelona, Spain. She is also an assistant research and psychotherapist at Sanitary Consortium of Maresme, Spain. Her research interests involve the role of emotional intelligence on mental disorders, psychopathologies and psychotherapeutics treatments.

Natalio Extremera, PhD is an associate professor at the Department of Social Psychology at University of Málaga, Spain. He is also an assistant research at the Research Unit for Emotional Intelligence at University of Málaga. His research interests involve the role of emotional intelligence on psychological adjustment, well-being, coping and health as well as the predictive validity of emotional abilities at workplace. 